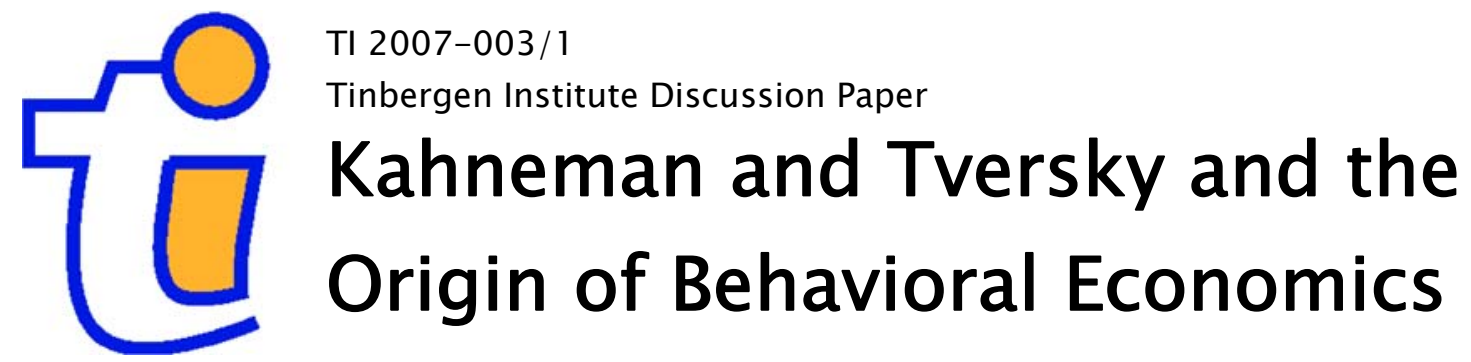

Floris Heukelom

Universiteit van Amsterdam, and Tinbergen Institute. 


\section{Tinbergen Institute}

The Tinbergen Institute is the institute for economic research of the Erasmus Universiteit Rotterdam, Universiteit van Amsterdam, and Vrije Universiteit Amsterdam.

Tinbergen Institute Amsterdam

Roetersstraat 31

1018 WB Amsterdam

The Netherlands

Tel.: $\quad+31(0) 205513500$

Fax: $\quad+31(0) 205513555$

Tinbergen Institute Rotterdam

Burg. Oudlaan 50

3062 PA Rotterdam

The Netherlands

Tel.: $\quad+31(0) 104088900$

Fax: $\quad+31(0) 104089031$

Most TI discussion papers can be downloaded at http:/ /www.tinbergen.nl. 


\title{
Kahneman and Tversky and the origin of behavioral economics
}

\author{
Floris Heukelom \\ Amsterdam School of Economics \\ Max Planck Institute for Human Development, Berlin
}

Version September 2006

\begin{abstract}
Kahneman and Tversky and their behavioral economics stand in a long tradition of applying mathematics to human behavior. In the seventeenth century, attempts to describe rational behavior in mathematical terms run into problems with the formulation of the St. Petersburg paradox. Bernoulli's celebrated solution to use utility instead of money marks the beginning of expected utility theory (EUT). Bernoulli's work is taken up by psychophysics which in turn plays an important role in the making of modern economics. In the 1940s von Neumann and Morgenstern throw away Bernoulli and psychophysics, and redefine utility in monetary terms. Relying on this utility definition and on von Neumann and Morgenstern's axiomatic constraints of the individual's preferences, Friedman and Savage attempt to continue Bernoulli's research. After this fails economics and psychology go separate ways. Economics employs Friedman's positive-normative distinction; psychology uses Savage's normativedescriptive distinction. Using psychophysics Kahneman and Tversky broaden the normativedescriptive distinction and argue with increasing strength for a descriptive theory of rational

\footnotetext{
${ }^{1}$ Please do not cite or distribute without permission. For helpful comments I thank Konstantinos Katsikopoulos, John Davis, Gerd Gigerenzer, Harro Maas and Tijmen Daniëls. I bear sole responsibility for any remaining mistakes. Correspondence: F.Heukelom@uva.nl
} 
behavior. A prominent part of contemporary behavioral economics is founded upon the export of Tversky and Kahneman's program to economics. Within this research, two different branches of research can be observed. One branch continues Kahneman and Tversky's search for a descriptive theory of rational behavior and extends the normative-descriptive distinction with a prescriptive part. A second branch takes Tversky and Kahneman's work as a falsification of positive economics. It argues that economics should take account of the psychological critique but stick to rigorous mathematical model building and Friedman's positive-normative distinction.

Behavioural economics ... is best understood as a set of exceptions that modifies but leaves intact the canonical model of rational choice, not least since it is irrational to suppose that people in general behave irrationally. The Economist, 29-04-2006

\section{Introduction}

This quote in The Economist illustrates behavioral economics' rapid rise to prominence. It is also a good example of the haziness in economists' understanding of this new research program. For how can behavioral economics at the same time modify and leave intact "the canonical model of rational choice"? And how can one modify the rational model whilst maintaining rationality?

This paper provides a basis for answering such questions by investigating the origins of behavioral economics. More specifically, I look at the origins and development of the theoretical work of two eminent researchers in contemporary behavioral economics: Daniel Kahneman and Amos Tversky. A clear line runs from the beginning of the mathematics of rational behavior in the seventeenth century to current debates in behavioral economics. I highlight the most important aspects of this research and show what Kahneman and Tversky take from and give to this research. Concluding remarks end the paper.

\section{The mathematics of rational behavior}

The behavioral economics of Kahneman and Tversky begins in 1654. In that year, noblemangambler Chevalier de Méré presents Blaise Pascal, and therewith Piere Fermat, with a number 
of gambling problems ${ }^{2}$. Upon de Méré's instigation, Pascal and Fermat discuss amongst others the following problem. Suppose two noblemen sit down to play a coin-tossing gamble in which the first to have two heads or tails wins, a game that ends after at most three tosses. Suppose further that for some reason the two noblemen-gamblers have to stop after one heads. What would in that case be a rational division of the money? Intuitively it is clear that the money should not be split equally because the player with heads has a larger chance of winning. But how much more should this player receive? When continued, the game could end in three ways: 1) heads (heads player wins), 2) tails, tails (tails player wins), 3) tails, heads (heads player wins). It thus seems that the money should be divided (2/3:1/3). The crucial conceptual insight, however, is to see that in fact there are four possibilities. We also have to consider the imaginary toss after the second toss turns heads. The complete number of possibilities is: 1) heads, heads (heads player wins), 2) heads, tails (heads player wins), 3) tails, tails (tails player wins), 4) tails, heads (heads player wins). A rational division of the money is thus (3/4:1/4). Contrary to for instance Samuelson (1977)'s view, determining the rational solution may involve quite a conceptual step

From the large body of literature on the Enlightenment mathematicians of probability it is well known that no distinction was made between determining the rational solution in situations of uncertainty, and the question of what a rational person would actually do in such situations $^{3}$. These two were one and the same thing. Hence, it was a major problem for the mathematics when it became clear that gambles could be constructed in which the rational solution provided by the mathematics was clearly at odds with the intuitive idea of the rational solution. The most famous example of these problems is the St. Petersburg paradox. Consider again the two noblemen who want to play a coin-tossing gamble. But suppose now that nobleman one proposes to nobleman two to pay him two ducats when the coin falls heads on the first toss, four ducats if it also falls heads on the second toss, eight ducats for the third heads, and so on ad infinitum until the coin turns up tails. Nobleman one, however, does not play this game for free and demands an entrance fee. When nobleman two wants to be rational, what is the entrance fee he is maximally willing to pay? The pay-off from this gamble is $\pi_{i}=2^{i}$, with $i$ the number of heads tossed; the probability is $p_{i}=\left(\frac{1}{2}\right)^{i} \cdot$ Combine both and the expected monetary gain $E(\pi)$ for nobleman two is

\footnotetext{
2 e.g Samuelson (1977)

3 e.g. Hacking (1975), Daston (1988), and Gigerenzer et.al (1989)
} 


$$
E(\pi)=\sum_{i=1}^{\infty} p_{i} \pi_{i}=\sum_{i=1}^{\infty}\left(\frac{1}{2}\right)^{i} 2^{i}=1+1+1+\ldots . .=\infty
$$

Hence, a rational nobleman two would be willing to pay all his wealth and all the wealth he will earn in the rest of his life as an entrance fee for this gamble. Intuitively everybody readily agrees that this is ridiculous. It simply cannot be rational to put the accumulated wealth of one's entire life in such a gamble. Something has to be wrong with the mathematics. But what?

A solution to the St. Petersburg was offered by Daniel Bernoulli in 1738. Bernoulli's idea was simple: do not use the objective value of the gamble, but use the subjective value, the utility.

"[T]he value of an item must not be based on its price, but rather on the utility it yields. The price of the item is dependent only on the thing itself and is equal for everyone; the utility however, is dependent on the particular circumstances of the person making the estimate. Thus there is no doubt that a gain of one thousand ducats is more significant to a pauper than to a rich man though both gain the same amount."4

Bernoulli defines utility to be a marginally increasing function of wealth, where wealth is loosely defined as the monetary value of all the individual's possessions plus the individual's capacities to earn money. The utility derived from a given monetary gain thus decreases with increasing initial wealth. In mathematical terms, ${ }^{5}$

$$
d U=c \frac{d W}{W}
$$

with $c$ a constant, $d U$ the change in utility, $W$ wealth, and $d W$ the change in wealth.

Graphically,

\footnotetext{
${ }^{4}$ Bernoulli (1738/1954), p.24

${ }^{5}$ This is a simplification of that part of Bernoulli's paper that is of relevance here. Bernoulli's paper and its 1954 English translation for Econometrica raise a number of in themselves interesting issues. See for instance Jallais and Pradier (2005), Jallais, Pradier, and Teira (manuscript), Teira (2005)
} 


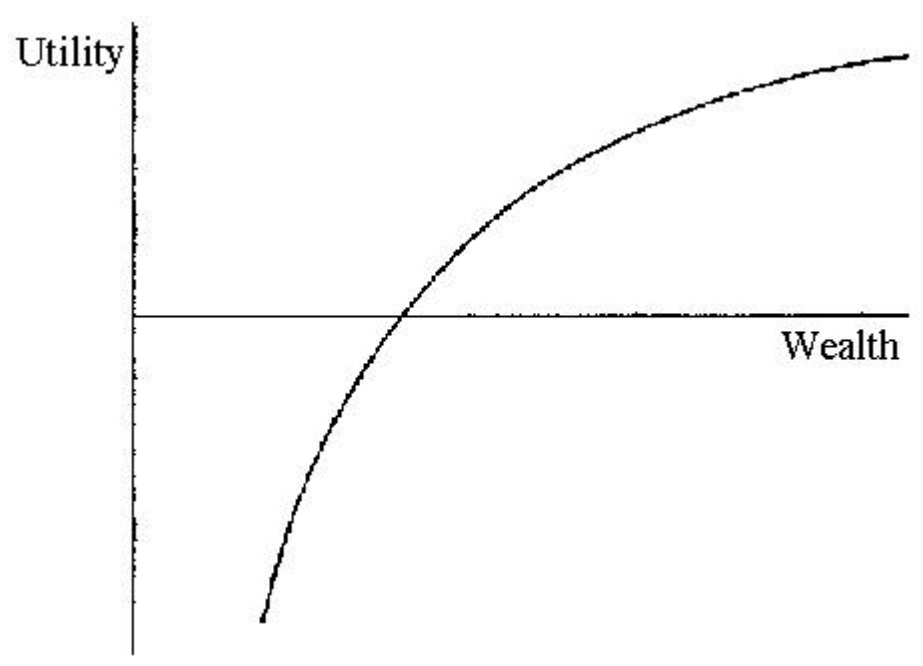

Figure 1. The figure is an adapted version from Bernoulli (1738/1954), p.26

When instead of the objective value of the monetary gain the subjective value of the utility is taken the mathematical expectation ${ }^{6}$ of the St. Petersburg paradox will not go to infinity but, depending on the exact parameters of equation 2, will asymptotically go to a number that is quite reasonable ${ }^{7}$. Bernoulli thus successfully introduced a theory of maximizing expected utility (EUT) as the basis for the study of rational decision behavior under uncertainty. Anachronistically, this may be seen as the beginning of decision theory.

\section{Psychophysics}

Bernoulli's relation between wealth and utility was corroborated by the work of the psychophysicists. In the middle of the 1850s Gustav Fechner, dissatisfied with the dominant Cartesian mind-body distinction, was looking for a more scientific basis for psychology ${ }^{8}$. His solution was to base psychology upon the idea that human beings should be seen as on the one hand receiving input from the world through their senses, and on the other hand producing output in the form of behavior. Fechner, in other words, invented the stimulusresponse paradigm. Now, it is clear that not every objective stimulus will evoke the same subjective sensation. An extra kilogram feels differently when one is already carrying five, or already carrying fifty kilograms. The first step in this new research paradigm therefore was to measure how external stimuli are perceived by human beings. The psychophysical law that

\footnotetext{
${ }^{6}$ The calculated expected utility is labeled 'moral expectation' by Bernoulli.

${ }^{7}$ The answer depends on the initial wealth of nobleman two and on the precise parameters of the utility function. Bernoulli estimates a typical maximum rational entrance fee of about 3 ducats.

${ }^{8}$ Murray (1993), Gigerenzer (1993)
} 
describes the relation between objective stimulus and subjective sensation that has become known as the Weber-Fechner law is the following.

$$
d S e=c \frac{d S t}{S t}
$$

where $d S e$ is the change in sensation, $S t$ the stimulus, $d S t$ the change in stimulus and $c$ a constant. Graphically,

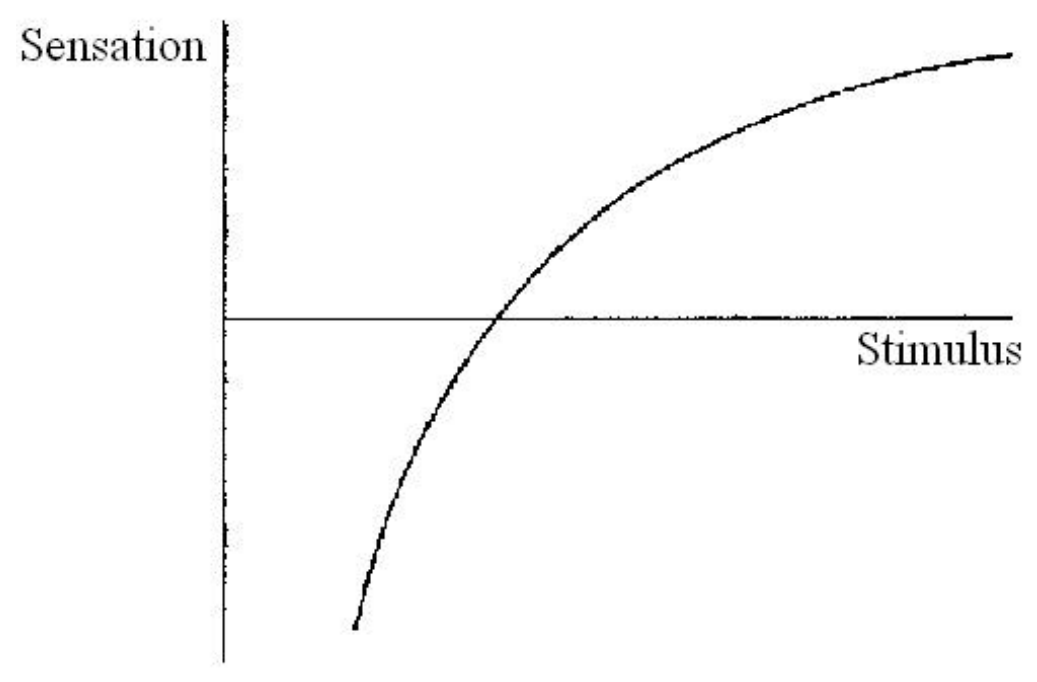

Figure 2, the psychophysical stimulus-sensation relation

Both the formula and the graph are similar to Bernoulli's relation between wealth and utility. Indeed, when we think of Bernoulli's wealth as the objective stimulus and utility as the subjective sensation it is not difficult to see how Bernoulli's paper anachronistically can be interpreted as the psychophysics of wealth and utility.

And this is precisely what was done by the English marginalists of the late nineteenth century ${ }^{9}$. A main source of inspiration for these scientists was utilitarianism, of which especially Bentham stands out as a dominant influence. Using psychophysics marginalists like Jevons and later Edgeworth sought to reduce Benthamite utility, which depended on seven factors, to a one-dimensional measurement scale of the individual perception of pleasure and pain $^{10}$. The English marginalists interpreted Bernoulli's solution to the St. Petersburg paradox as the psychophysics of wealth and utility and at the same time used psychophysics to reduce

\footnotetext{
${ }^{9}$ Blaug (1996), p.316-318. Like Blaug (1996) I am making some very rigorous historcial shortcuts here. For extensive discussions on the relation between English marginalists, Benthamite utilitarianism, psychophysics and psychophysiology see Maas (2005), Sigot (2002), Warke (2000)

${ }^{10}$ Cohen (1997)
} 
Benthamite utility to a one-dimensional measurement scale of utility for hedonic pleasure seeking and pain avoiding individuals. Therewith psychophysics connected the mathematics of human behavior with the utility of utilitarianism.

\section{Von Neumann and Morgenstern}

One of the most important books in the social sciences of the twentieth century is without any doubt von Neumann and Morgenstern's Theory of Games and Economic Behavior (1944). Game theory is an extension of decision theory to situations in which the rational decision depends on behavior of other agents. Von Neumann and Morgenstern (1944) shows that also in games in which the uncertainty is endogenous it is possible to say something about what is rational behavior ${ }^{11}$. Such games include Bridge, Chess, strategic price setting behavior of firms, and nuclear arms races during cold wars.

In the book, von Neumann and Morgenstern first assume for reasons of simplification utility to be equivalent with money.
"We wish to concentrate on one problem - which is not that of the measurement of utilities and of preferences- and we shall therefore attempt to simplify all other characteristics as far as reasonably possible. We shall therefore assume that the aim of all participants in the economic system, consumers as well as entrepreneurs, is money, or equivalently a single monetary commodity. This is supposed to be unrealistically divisible and substitutable, freely transferable and identical, even in the quantitative sense, with whatever "satisfaction" or "utility" is desired by each participant."12 (emphasis added)

With regard to the unit of analysis von Neumann and Morgenstern (1944) thus effectively turn the clock back to before Bernoulli, when the rational decision depended on the absolute, objective value of money. For von Neumann and Morgenstern (1944) the agents in decision problems, games and the economy generally want to maximize their monetary income, not their Bernoullian utility. However, in a move that stands in a long history of concept-juggling von Neumann and Morgenstern (1944) label this money 'utility'. Von Neumann and

\footnotetext{
${ }^{11}$ See for an illuminating example of the transition from decision theory to game theory the translation of Borel's papers for Econometrica in Frechet (1953).

12 Von Neumann and Morgenstern (1944), p.8
} 
Morgenstern's agents maximize money, or monetary equivalents, but this money is called utility $^{13}$.

Secondly, von Neumann and Morgenstern (1944) construct a set of formal constraints on the relation between the preferences of the agents in their games. This set of constraints is best seen as a specification of assumptions that had been left unspecified or implicit in the earlier work on the mathematics of rational decision behavior. Along von Neumann and Morgenstern (1944) there exist many other, related axiomatic sets. The formal set of constraints of von Neumann and Morgenstern (1944) and others can furthermore be integrated with the axiomatic constraints for decision behavior under certainty as presented by for instance Samuelson (1947). That said, the axioms of von Neumann and Morgenstern (1944) are not yet as worked out and as neatly written down as they have been by later authors. However, all contain in one form or another, implicitly or explicitly, each of the following elements ${ }^{14}$. i) The preference ordering assumption. This assumption holds that in a set of options there always is a preference ordering. ii) The choice according to preference assumption. This assumption states that if an individual prefers one option over another, she chooses that option. iii) The transitivity assumption. This assumption holds that the preference ordering of the individual is consistent. That is, that the preferences do not contradict one another. iv) The independence of irrelevant alternatives assumption. This means that the individual's preference is independent of other considerations, including other options. v) The invariance assumption. For the preference relation it does not matter how the options are presented as long as the different presentations are logically equivalent.

\section{Friedman and Savage}

Milton Friedman and Leonard Savage write two articles together that are an indicative precursor to much of subsequent developments in the theories of rational decision behavior in economics and psychology. ${ }^{15}$ Economist Friedman and mathematician Savage adhere to two different views on how to approach rational economic behavior under uncertainty. Friedman adheres to the received methodological distinction in economics between positive and

\footnotetext{
${ }^{13}$ Alternatively, one could say that the value used for the calculation is objective in pre-Bernoullian times, subjective following Bernoulli, and again objective after von Neumann and Morgenstern.

${ }^{14}$ A difficulty with the mathematics of the axiomatic constraints as set out by von Neumann and Morgenstern (1944) and others is that one either needs to discuss it extensively, or forego any formal notation. For reasons of space and because it is not directly the subject of the paper, I choose the latter. Furthermore, I have to leave for another occasion a discussion on the influential role of logicians such as Frank Ramsey in the development of the axiomatic constraints. For useful overviews of the mathematics see for instance Mas -Colel (1995) and Fishburn (1981).

${ }^{15}$ Friedman and Savage $(1948,1952)$
} 
normative. It is the distinction between the science of economics and the art of economics as argued for by for instance J.S. Mill (1844), or the distincttion between theorizing with the norms fixed and theorizing about the norms, as argued for by for instance Robbins (1932). Savage on the other hand adheres to the $a$ priori approach of mathematics ${ }^{16}$, which goes back to Kant's distinction between a priori and a posteriori knowledge ${ }^{17}$. An a priori theory is true because it is true by (logical) definition, without any directly associated empirical content. The positive-normative and the a priori approach towards a mathe matical theory on human behavior are, however, by no means incompatible. As long as the theory is not disproved by empirical or theoretical counter argument, it can perfectly well function as a positive theory in economics and as an a priori theory in (applied) mathematics. This is precisely what happened in Friedman and Savage (1948, 1952).

Accepting von Neumann and Morgenstern's utility concept and axiomatic approach, Friedman and Savage put themselves in the tradition of "Bernoulli's celebrated analysis of the St. Petersburg paradox"18, but broaden this research by including all (economic) choice situations that involve uncertainty of some sort. The basic problem they want to address is the fact that although an accomplished result, Bernoulli's concave utility functions can only explain insurance, not gambling. That is, Bernoulli's utility function offers an explanation for the fact that people are willing to pay money to reduce risk, but therewith also supposes that people will not engage in fair, or less than fair gambles. This is a problem that goes beyond insurances and gambles. In order to explain the co-existence of both risk-averse and riskseeking behavior the utility function would have to be concave and convex at the same time. One could solve this problem by observing that the amounts of money for which people insure themselves are typically lower than the often very high amounts of money people can win in gambles and lotteries. In that case, Bernoulli's concave utility function is followed by a convex part. But then one forgets, as Friedman and Savage quickly observe, that in lotteries there often is a range of prices, including relatively low prices. The only way to rationalize this behavior is a "wiggly utility curve" that describes people as risk-averse for low incomes, risk-seeking for higher incomes, and again risk-averse for the highest incomes.

\footnotetext{
16 Jallais and Pradier (2005)

${ }^{17}$ Hanna (2004)

${ }^{18}$ Friedman and Savage (1948), p.281
} 


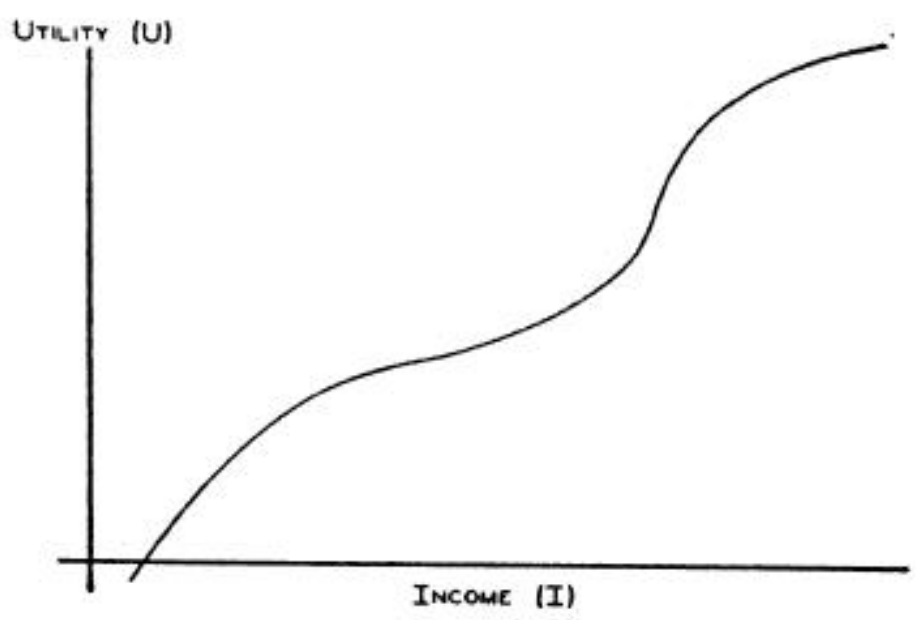

Figure 2, Friedman and Savage (1948), p.297

An obvious objection that can be raised upon the construction of such a utility curve is that it is "patently unrealistic to suppose that individuals consult a wiggly utility curve before gambling or buying insurance." ${ }^{, 19}$ In the answer of Friedman and Savage to this self-imposed objection one can clearly see the precursors of the methodological arguments for which the two independently would become (in)famous in later years. Friedman's as-if argument and Savage's struggles with empirical falsification are already neatly spelled out.

"While entirely natural and understandable, this objection is not strictly relevant. The hypothesis does not assert that individuals explicitly or consciously calculate and compare expected utilities. Indeed it is not at all clear what such an assertion would mean or how it could be tested. The hypothesis asserts rather that, in making a particular class of decisions, individuals behave as if they calculated and compared expected utility and as if they knew the odds.

Stated differently, the test by results is the only possible method of determining whether the as if statement is or is not a sufficiently good approximation to reality for the purpose at hand.

Whatever the psychological mechanism whereby the individuals make choices, these choices appear to display some consistency, which can apparently be described by our utility hypothesis. This hypothesis enables predictions to be made about phenomena on which there is not reliable evidence. The hypothesis cannot be declared invalid for

\footnotetext{
${ }^{19}$ Friedman and Savage (1948), p.297
} 
a particular class of behavior until a prediction about that class proves false. No other test of its validity is decisive." 20

For the economist Friedman an explanation in terms of a wiggly utility curve works fine as a positive theory which function it is to provide an as-if description on the basis of which reliable predictions can be made. For the mathematician Savage an explanation in terms of a wiggly utility curve is fine because it is logically consistent and not in disaccord with casual empirical observation.

A test of the theory's validity was presented to Savage by Maurice Allais over lunch, during a conference in Paris in 1952. Allais made Savage fill out a list of questions with which he could show that Savage violated his own theory. The history of Allais' paradox (as it became known) is in itself intriguing. It seems that several other researchers, amongst whom Friedman, when presented with the same questions some months later passed the test. Furthermore, the Allais paradox remained practically unknown until some twenty years $\operatorname{later}^{21}$. But what was decisive for subsequent developments in economics and psychology, was that Savage took the critique of Allais seriously whereas Friedman, as far as I can tell, put the whole subject aside. Friedman left EUT as a basis for decision and game theory without further comments as a positive (as-if) theory; Savage retreated into a normative account of the theory.

In The Foundations of Statistics (1954) Savage lays the basis for research in decision theory in psychology for decades to come. In the book Savage maintains that decision theory is about rational behavior, but instead of an a priori theory it is now to be thought of as a normative theory. Decision theory "can [firstly] be regarded as a prediction about the behavior of people, or animals, in decision situations. Second, it can be regarded as a logiclike criterion of consistency in decision situations. For us, the second interpretation is the only one of direct relevance, but it may be fruitful to discuss both, calling the first empirical and the second normative." 22 Normative for Savage here means that although individual people may deviate from the theory, they will recognize their error and adjust their behavior as soon as the theory is explained to them ${ }^{23}$. For Savage, and for the psychologists building on his work, decision theory continued to be a theory of rational decision behavior under uncertainty, but with the pre-caution that the theory holds normatively, not necessarily

\footnotetext{
${ }^{20}$ Friedman and Savage (1948), p.297-298, their italics.

21 Jallais and Pradier (2005).

${ }^{22}$ Savage (1954), p.19

${ }^{23}$ Savage (1954), P.101-103, Jallais and Pradier (2005)
} 
descriptively. Note that this solution is different from Bernoulli's. Bernoulli saved the mathematics from the St. Petersburg paradox by adjusting the meaning of the mathematical symbols. Savage saves the mathematics from Allais' paradox by changing the interpretation of the theory.

\section{Kahneman and Tversky}

After the 1952 Paris conference with Allais economics and psychology went separate ways. Economics maintained EUT within the positive-normative distinction as a positive as- if theory of rational human behavior, psychology started to use EUT as a normative theory from which behavior by people in the real world who do not (yet) know the theory may differ. This marks the beginning of some thirty years during which psychologists and economists using EUT talk little, if at all to one another.

Although the psychologists following Savage recognize that decision theory is a normative theory, they do in first instance not denounce it completely as a descriptive theory, quite the contrary. Ward Edwards, one of the main decision theorists in psychology during the 1950s and 1960s, concludes that people behave largely in line with the normative theory. The only situation in which they can really be said to deviate from the normative theory is in their handling of new information of uncertain events. In those situation people are systematically more conservative than they should. For the rest, however, subjects' behavior in experiments is pretty much in accordance with the normative theory ${ }^{24}$. Another characteristic of the first twenty years after Savage is that the experiments conducted by the psychologists are confined to so-called 'small world' situations, a term from Savage (1954), in which the task and the description of the task are always clearly logical and probabilistic. Experiments typically involve urns with poker chips of different colors on the basis of which subjects have to compute some probability distribution.

Both these characteristics change with the research of Kahneman and Tversky. In the 1960s, Kahneman is predominantly working on the psychophysics of vision and, related, on semantic differential (SD) research ${ }^{25}$. In both of these research domains the question is how humans perceive objectively given stimuli and, especially in the case of vision, what perceptual errors may occur. For instance, in a series of follow-up articles Kahneman shows that the subjective perception of a visual stimulus depends on how busy an individual is

\footnotetext{
${ }^{24}$ Edwards (1954,1961)

25 e.g. Kahneman (1963;1966a,b), Kahneman and Norman (1967), and Kahneman and Beatty (1967)
} 
performing other tasks ${ }^{26}$. If you give people some simple math problems to solve they are less likely to perceive a weak visual stimulus as compared to when they are not engaged in sucha task. This could for example be a confirmation of the intuitive observation that car drivers engaged in busy conversation are more likely to miss a traffic light than are care drivers that are not. Kahneman in other words uses psychophysics to show that under certain conditions people make mistakes in their perception of objective stimuli.

During the 1960s, Tversky for his part works predominantly on the theoretical exploration and development of EUT, both as a normative and as a descriptive theory, and on the development of a theory of measurement for the empirical investigation of normative EUT's descriptive merits. Concerning the normative theory, Tversky is working on the further precision and development of the axiomatic structure ${ }^{27}$. Important questions here are which mathematical structure is most appropriate to formalize the assumptions, whether there are perhaps some implicit assumptions that have been left unspecified, and what is mathematically the best way to relate the different axiomatic assumptions to one another. In Tversky's work on measurement theory the central question is how to mathematically formulate the homomorphous relation between world and representation in such a way that it is mathematically sound and at the same time allows for simultaneous measurement of (subjective) probability and utility ${ }^{28}$. The fact that Tversky quickly rises to a prominent position in this research is illustrated by his participation in the well-known Foundations of Measurement $(1971)^{29}$.

The different lines of research of Kahneman and Tversky come together in their collaborative work of the $1970 \mathrm{~s}^{30}$. Tversky and Kahneman first of all expand the experiments of the psychology on decision theory to more real-world situations. Subjects are no longer asked to update their beliefs in the probability distribution of poker chips in an urn on the basis of a sequence of draws from the urn, but are given problems involving uncertainty that are meant to relate directly to the subjects' real-world acquaintance with uncertainty. For instance, in their famous first publication Tversky and Kahneman ask psychologists during a major psychology conference in the USA for a judgment of the degree of certainty of a surprising psychological finding after a certain number of experiment $s^{31}$. Secondly, Tversky

\footnotetext{
26 e.g. Kahneman et.al. (1967), Kahneman and Peavler (1969)

27 e.g. Tversky (1969), Tversky and Russo (1969)

28 e.g. Tversky (1967a,b), Pollatsek and Tversky (1970), Tversky and Krantz (1970), and Krantz and Tversky (1971)

${ }^{29}$ Krantz et. al (1971). Volumes II and II appear in 1989 and 1990.

30 Tversky and Kahneman $(1971,1973,1974,1977)$ and Kahneman and Tversky $(1972,1973,1979)$

${ }^{31}$ Tversky and Kahneman (1971)
} 
and Kahneman start to make a clearer distinction between the normative solution to a problem and the subjective answer given by real-world individuals. Increasingly, the normativedescriptive distinction becomes a psychophysical distinction between a normative theory that is about what is objectively correct, and a descriptive theory that is about what is subjectively perceived. Deviations from the normative theory by implication are more clearly distinguished as errors.

The research lines of Tversky and Kahneman thus neatly commensurate. Tversky's mathematical work on the normative theory and on the measurement of actual choices fit with Kahneman's psychophysical emphasis on the difference between the objective stimulus and the subjective sensation. The resulting greater emphasis on the difference between a normative and a descriptive theory of decision making has two consequences. Firstly, it allows Kahneman and Tversky to expand psychology's experiments on decision making to more real world situations. Secondly, the more systematic deviations with respect to the normative theory Kahneman and Tversky find can be explained in terms of the perceptual errors Kahneman was already working on. A deviation from EUT as a normative theory becomes an example of a phenomenon that is already well-known from psychophysical research.

With their publication in Econometrica in 1979 Kahneman and Tversky export their findings to economics. Rhetorically, it is a clever article. It tells the economists that EUT as a positive theory systematically deviates from real-world decision behavior of human beings. For economists who do not care about the descriptive realism of a theory but are only interested in its predictive merits the systematic deviations are a decisive argument. The article also marks the beginning of a more conscious attempt of Tversky and Kahneman to come to a complete rationalization of reat world decision behavior of human beings. This descriptive theory, labeled prospect theory, with increasing explicitness turns the clock back to before von Neumann and Morgenstern (1944). Utility in prospect theory is not an absolute given but depends on the individual's subjective perception ${ }^{32}$. Prospect theory therewith brings us back to Bernoulli. In case of the subjective perception of utility (labeled 'value') the relation looks as follows.

\footnotetext{
${ }^{32}$ Also for probability a distinction is made between the objective and the subjective value.
} 


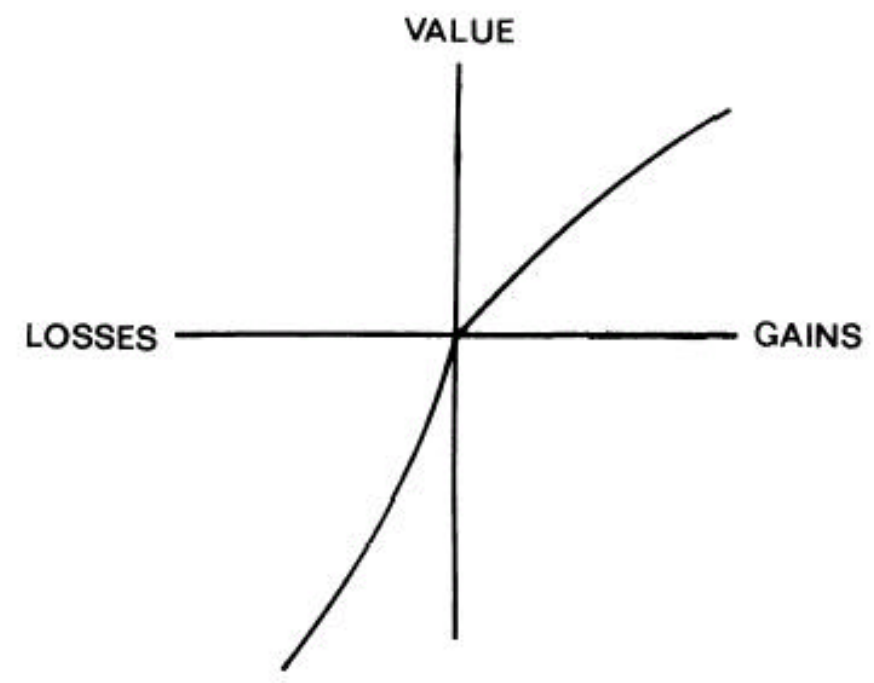

Figure 4, Kahneman and Tversky (1979), p.279

\section{Kahneman and Tversky's Behavioral Economics}

Behavioral economics on the basis of Tversky and Kahneman's work emerges halfway the 1980s. ${ }^{33}$ An important sponsor of this research is the Russell Sage Foundations (RSF). The RSF maintains a 'Behavioral Economics Roundtable' that consists of scientists that contribute to Tversky and Kahneman-based behavioral economics. Along Kahneman and Tversky (until his death in 1996) this roundtable includes among others Richard Thaler, Colin Camerer, Matthew Rabin, David Laibson, Sendhil Mullainathan, and George Loewenstein. Despite its close adherence to the work of Tversky and Kahneman, however, the research produced by roundtable members can methodologically be divided into a group that follows the psychologists' normative-descriptive distinction, and a group that follows economics' positive-normative distinction.

Main figures in the first group are Tversky and Kahneman themselves, and economists like Thaler, Sunstein, and Sugden. In this research the psychophysical distinction between the normative (objective), and the descriptive (subjective) theory becomes more and more pronounced. As it has been shown time and again that individuals' subjective perception of utility and probabilities are different from their objective values, the main focus of the psychological line is to conceptually define and measure subjective utilities and probabilities $^{34}$. To distinguish between the utility of the normative and the descriptive theory, Kahneman from the beginning of the 1990s onwards argues for a conceptual distinction

\footnotetext{
${ }^{33}$ See Sent (2005) for an overview of research that employs the term Behavioral Economics.

${ }^{34}$ This prgram is set out in for instance Tversky and Kahneman (1986), Quattrone and Tversky (1988), Tversky and Kahneman (1992), and Kahneman (2003),
} 
between 'decision utility' and 'experienced utility ${ }^{35}$. Decision utility refers to the standard use of utility in decision theory and can be equated with the utility concept of von Neumann and Morgenstern (1944). It is the objective monetary value of an option or the representation of this option in monetary terms. The subjectively perceived utility is called 'experienced utility'. As said, history therewith partly repeats itself. Like Bernoulli, who argued that the objective monetary value of an option cannot be a good measure of decision behavior, Kahneman argues that the objective von Neumann-Morgenstern 'decision utility' has proven not to be a good basis for a descriptive theory of rational decision behavior. Where Bernoulli reasons that the subjective value of the monetary loss or gain should be the basis of the calculation, so Kahneman argues that only the subjective 'experienced utility' can be a good basis for a descriptive theory. Tversky for his part continues to explore the subjective perception of probability ${ }^{36}$. Here there seems not to be a clear name for the subjective perception, although an often used term is 'decision weight'.

A consequence of the more pronounced distinction between normative and descriptive in Kahneman and Tversky is that 'normative' no longer means that people recognize and admit their errors when the theory is explained to them, as it meant for Savage. In Tversky and Kahneman's distinction people may persistently not understand what they do wrong, even when the normative solution is repeatedly explained to them. When the problems subjects are faced with are relatively harmless hypothetical situations about cabs and Linda's this does not really matter. However, when the problem is a reallife situation in which the wrong decision can have serious (economic) consequences, this is of more immediate concern. Think of the truck driver who misses a traffic light. The question then becomes how individuals can be persuaded or induced to behave more in accordance with the normative theory. For instance, people say they want to save for retirement, but at the same time can be observed not to do so. The question then is what kind of policy could be implemented that makes individuals behave more in accordance with the normative solution of saving a certain amount of money per $\operatorname{month}^{37}$.

To cut the story short, in an extension to the normative-descriptive distinction, Kahneman and his collaborators in RSF behavioral economics argue for a 'prescriptive' theory of decision-making ${ }^{38}$. They promote a re-interpretation of economics in terms of a

\footnotetext{
35 e.g. Kahneman (1994, 2003), Kahneman, Wakker, and Sarin (1997)

${ }^{36}$ e.g. Simonson and Tversky (1992), Tversky and Wakker (1995), Fox and Tversky (1995), Wakker, Thaler, and Tversky (1997)

37 e.g. Cronqvist and Thaler (2004)

38 e.g. Kahneman and Thaler (1991), Thaler and Sunstein (2003), Kahneman and Sugden (2005)
} 
normative-descriptive-prescriptive distinction. 'Normative' is what is objectively correct and how people should and either consciously or unconsciously want to behave. 'Descriptive' is how people actually behave in reality. Deviations of real world behavior from the normative theory may occur for a number of reasons and are not likely solved by explaining the theory to the individuals. 'Prescriptive', then, is about how policies should be designed in order to make people behave more in accordance with the normative theory.

A second line of research in the RSF behavioral economics of Kahneman and Tversky argues for the continuation of economics' positive-normative distinction. Prominent behavioral economists like Camerer, Fehr and Rabin reason that economics should take account of the psychological research that shows EUT to be incorrect as a positive theory. But for these economists this implies that the traditional EUT is to be discarded completely, that is, both positively and normatively.

A good example of this approach is the research on hyperbolic discounting. In the traditional economic theory people are described as if they discount future income exponentially. However, it turns out that realworld behavior systematically deviates from this theory. The dis count factor for a financial gain in thirty-one instead of thirty days from now is lower than the discount factor for a financial gain tomorrow instead of today. Realworld individuals are hence better described as-if they discount hyperbolically. Economists should therefore adjust their positive theory in such a way that it accounts for hyperbolic discounting ${ }^{39}$. Thus Laibson notes that

"[The theory of exponentially discounted utility] has normative and positive content. It has been proposed as both a description of what people should do to maximize their well-being, and to describe what people actually do when faced with intertemporal decisions. Both applications of the model are controversial., 40

This is where it gets a bit fuzzy because Laibson and other RSF behavioral economists follow both Kahneman and Tversky's understanding of normative-descriptive, as well as economics' positive-normative distinction. These economists still see economics as a scientific basis for policy making. J.S. Mill's 'art of economics' firmly stands, and normative remains the term to refer to this (applictaion of positive) economics. At the same time, they recognize that 'positive' covers a normative and a descriptive sub-domain, where traditional economics fails

\footnotetext{
${ }^{39}$ e.g. Laibson (1997), O’Donoghue and Rabin (1999), Frederick, Loewenstein and O’Donoghue (2002)

${ }^{40}$ Laibson (2003), p.3.
} 
in both. Traditional economic theories, then, can at most function as a "special case" of a more general positive theory ${ }^{41}$. Once this theory is there, it could again be used as a basis for normative economics.

This second branch in behavioral economics remains firmly in the traditional positivenormative distinction of economics. It admits that the positive theory as traditionally used by economic fails and that economists should thank psychology for correctly pointing to the fact that behavior of real-world individuals systematically deviates from the predictions of traditional economic theory. Psychology has furthermore correctly encouraged economics to test their theories experimentally before adopting them. But given these insights from psychology, (behavioral) econo mics should go back to what it is good at. According to this second line of research within RSF behavioral economics, economics is not the same as psychology and should neither aim to become so. Economics does its experiments differently and uses more rigorous mathematics ${ }^{42}$. Given the findings of psychology, economics should go back to concise model building in order to create positive theories that provide good predictions $^{43}$.

\section{Conclusion}

Kahneman and Tversky and their behavioral economics stand in a long tradition of explaining human behavior in mathematical terms. The problems that the initial attempt to describe rational human behavior in mathematical term ran into were partly resolved by Bernoulli's suggestion that the value of a monetary loss or gain depends on the personal circumstances of the individual. His work was picked up by psychophysicists and interpreted as the psychophysics of wealth and utility. Psychophysics in turn formed an important element in the founding by the English marginalists of what would become modern economics.

In the 1940s von Neumann and Morgenstern threw away this psychophysical research and defined human behavior again in terms of the pursuit of money. Friedman and Savage used the work of von Neumann and Morgenstern to pick up where Bernoulli had stopped, but did so for slightly different reasons. The mathematician Savage wanted a mathematically sound description of rational human decision behavior under uncertainty. The economist Friedman wanted an as-if theory that yields good predictions. Faced with Allais' critique, Savage retreated into a normative interpretation of the theory. Friedman, and the rest of the

\footnotetext{
${ }^{41}$ Camerer and Loewenstein (2004)

42 e.g. Camerer (1997), Loewenstein (1999)

${ }^{43}$ Rabin (1998), Camerer and Loewenstein (2004)
} 
economic community with him, continued to use EUT as a basis for positive theories that predict well.

The work of Kahneman and Tversky, then, is to be seen in the psychological research that built upon Savage's work. However, using psychophysics Tversky and Kahneman made the difference between normative and descriptive theory more pronounced. Their 1979 Econometrica article marks the beginning of a project to come to a full descriptive theory of rational human behavior along the existing normative theory. One branch of the RSF behavioral economics founded upon their work continues this research and has in recent years extended the normative-descriptive distinction with a third 'prescriptive' part that tells how people can be made to behave more in accordance with the normative theory. A second branch of RSF behavioral economics, however great their gratitude to Kahneman and Tversky, continues to work in the Friedman tradition of economics. It argues that (behavioral) economics should gratefully integrate psychology's suggestions, but then return to the building of positive, mathematical theories that yield good predictions.

The anonymous author of The Economist, cited at the beginning of the article, is thus partly right. Behavioral economics is about rational behavior. However, looking at the RSF behavioral economics founded upon the work of Kahneman and Tversky, one branch leaves "the canonical model of rational choice" intact but searches for a descriptive counterpart. A second branch modifies "the canonical model", and thus does not leave it intact. 


\section{References}

- Anonymous. (2006). The perils of prosperity. The Economist, pp. 82-83.

- Bernoulli, D. (1738/1954). Exposition of a New Theory on the Measurement of Risk. Econometrica, 22(1), 23-36.

- Blaug, M. (1997). Economic theory in retrospect, 5th ed. Cambridge: Cambridge University Press.

- Camerer, C. (1997). Rules for Experimenting in Psychology and Economics. In W. Albers, W. Güth, P. Hammerstein, B. Moldovanu \& E. v. Damme (Eds.), Understanding Strategic Interaction, essays in honor of Reinhard Selten (pp. 313327). Berlin: Springer.

- Camerer, C., \& Loewenstein, G. (2004). Behavioral Economics: Past, Present, Future. In C. F. Camerer, G. Loewenstein \& M. Rabin (Eds.), Advances in Behavioral Economics (pp. 3-52). Princeton: Princeton University Press.

- Cohen, J. (1997). Utility: a real thing. University of Amsterdam, Amsterdam.

- Cronqvist, H., \& Thaler, R. (2004). Design Choices in Privatized Social-Security Systems: Learning from the Swedish Experience. American Economic Review, papers and proceedings, 94(2), 424-428.

- Daston, L. (1988). Classical Probability in the Enlightenment. Princeton: Princeton University Press.

- Edwards, W. (1954). The Theory of Decision Making. Psychological Bulletin, 51, 380-417.

- Edwards, W. (1961). Behavioral decision theory. Annual Review of Psychology(12), 473-498.

- Fehr, E., \& Gachter, S. (2001). Fairness and Retaliation: The Economics of Reciprocity. Journal of Economic Perspectives, 14(3), 159-181.

- Fishburn, P. C. (1981). Subjective expected utility: a review of normative theories. Theory and Decision, 13, 139-199.

- Fox, C., \& Tversky, A. (1995). Ambiguity Aversion and Comparative Ignorance. The Quarterly Journal of Economics, 110(3), 585-603.

- Frechet, M., \& Borel, E. (1953). Emile Borel, Initiator of the Theory of Psychological and its Applications. Econometrica, 21, 95-125.

- Frederick, S., Loewenstein, G., \& O'Donoghue, T. (1999). Time Discounting: A Critical Review. Journal of Economic Literature, 40(2), 351-401.

- Friedman, M., \& Savage, L. (1948). The utility analysis of choice involving risk. Journal of Political Economy(LVI 4), 279-304.

- Friedman, M., \& Savage, L. (1952). The expected-utility hypothesis and the measurability of utility. Journal of Political Economy(LX 6), 463-474.

- Gigerenzer, G. (1993). From metaphysics ot psychophysics and statistics. The behavioral and brain sciences, 16(1), 139-140.

- Gigerenzer, G., Swijtink, Z., Porter, T., Daston, L., Beatty, J., \& Krüger, L. (1989). The Empire of Chance. Cambridge: Cambridge University Press.

- Hacking, I. (1975). The Emergence of Probability. London: Cambridge University Press.

- Hanna, R. (2004). Kant's Theory of Judgment. In The Stanford Encyclopedia of Philosophy: The Metaphysics Research Lab, Center for the Study of Language and Information, Stanford University, http://plato.stanford.edu/.

- Jallais, S., \& Pradier, P.-C. (2005). The Allais Paradox and its immediate consequences for expected utility theory. In P. Fontaine \& R. Leonard (Eds.), The Experiment in the History of Economics. New York: Routledge. 
- Jallais, S., Pradier, P.-C., \& Teira, D. (manuscript), Facts, Norms and Expected Utility Functions

- Kahneman, D. (1963). The semantic differential and the structure of inferences among attributes. American Journal of Psychology, 76, 554-567.

- Kahneman, D. (1966a). Time-intensity reciprocity in acuity as a function of luminance and figure-ground contrast. Vision Research, 6, 207-215.

- Kahneman, D. (1966b). Time-intensity reciprocity under various conditions of adaptation and backward masking. Journal of Experimental Psychology, 71, 543-549.

- Kahneman, D. (1994). New Challenges to the Rationality Assumption. Journal of institutional and theoretical economics, 150(1), 18-44.

- Kahneman, D. (2003). Maps of Bounded Rationality: Psychology for Behavioral Economics. The American Economic Review, 93(5), 1449-1475.

- Kahneman, D., \& Beatty, D. (1967). Pupillary responses in a pitch-discrimination task. Perception and Psychophysics, 2, 101-105.

- Kahneman, D., Beatty, D., \& Pollack, I. (1967). Perceptual deficit during a mental task. Science, 157, 218-219.

- Kahneman, D., \& Norman, J. (1967). Critical duration for the resolution of form: centrally or peripherally determined. Journal of Experimental Psychology, 73(3), 323327.

- Kahneman, D., \& Peavler, W. S. (1969). Incentive effects and pupillary changes in association learning. Journal of Experimental Psychology, 79(2), 312-318.

- Kahneman, D., \& Sugden, R. (2005). Experienced Utility as a Standard of Policy Evaluation. Environmental \& Resource Economics, 32, 161-181.

- Kahneman, D., \& Thaler, R. (1991). Economic Analysis and the Psychology of Utility: Applications to Compensation Policy. The American Economic Review, 81(2), 341-346.

- Kahneman, D., \& Tversky, A. (1972). Subjective Probability: A Judgment of Representativeness. Cognitive Psychology, 3, 430-454.

- Kahneman, D., \& Tversky, A. (1973). On the Psychology of Prediction. Psychological Review, 80, 237-251.

- Kahneman, D., \& Tversky, A. (1979). Prospect Theory: An Analysis of Decision under Risk. Econometrica, 47, 313-327.

- Kahneman, D., Wakker, P., \& Sarin, R. (1997). Back to Bentham? Explorations of Experienced Utility. The Quarterly Journal of Economics, 112(2), 375-405.

- Krantz, D. H., Luce, R. D., Suppes, P., \& Tversky, A. (1971). Foundations of Measurement (Vol. I). New York: Academic Press.

- Krantz, D. H., \& Tversky, A. (1971). Conjoint-measurement analysis of composition rules in psychology. Psychological Review, 78(2), 151-169.

- Laibson, D. (1997). Golden Eggs and Hyperbolic Discounting. Quarterly Journal of Economics, 112, 443-477.

- Loewenstein, G. (1999). Experimental Economics from the vantage-point of Behavioural Economics. The Economic Journal, 109, F25-F34.

- Maas, H. (2005). Mill and Jevons on the Private Laboratory of the Mind. The Manchester School, 620-649.

- Mas-Collel, A., \& Whinston, M. D. (1995). Microeconomic Theory. New York: Oxford University Press.

- Mill, J. S. (1844). On the definition of Political Economy; and on the method of investigation proper to it. In J. S. Mill (Ed.), Essays on some unsettled questions of political economy. London: Longmans. 
- Murray, D. (1993). A perspective for viewing the history of psychophysics. The behavioral and brain sciences, 16(1), 115-136.

- Neumann, J. v., \& Morgenstern, O. (1944). Theory of Games and Economic Behavior. Princeton: Princeton University Press.

- O'Donoghue, T., \& Rabin, M. (1999). Doing it Now or Later. The American Economic Review, 89(1), 103-124.

- Pollatsek, A., \& Tversky, A. (1970). A Theory of Risk. Journal of Mathematical Psychology, 7, 540-553.

- Quattrone, G., \& Tversky, A. (1988). Contrasting Rational and Psychological Analyses of Political Choice. The American Political Science Review, 82(3), 719-736.

- Rabin, M. (1993). Incorporating Fairness into Game theory and Economics. American Economic Review, 83(5), 1281-1302.

- Rabin, M. (1998). Psychology and Economics. Journal of Economic Literature, 36(1), 11-46.

- Robbins, L. (1932), An essay on the nature \& significance of economic science. London: Macmillan.

- Samuelson, P. A. (1947). Foundations of Economic Analysis. London: Oxford University Press.

- Samuelson, P. A. (1977). St. Petersburg Paradoxes: Defanged, Dissected, and Historically Described. Journal of Economic Literature, 15(1), 24-55.

- Savage, L. (1954). The Foundations of Statistics. London: Chapman \& Hall.

- Sent, E.-M. (2004). Behavioral Economics: How psychology made its (limited) way back into economics. History of Political Economy, 36(4), 735-760.

- Sigot, N. (2002). Jevons's debt to Bentham: Mathematical Economy, Morals and Psychology. The Manchester School, 70(2), 262-278.

- Simonson, I., \& A. Tversky. (1992). Choice in Context: Tradeoff Contrast and Extremeness Aversion. Journal of Marketing Research, 29(3), 281-295.

- Teira, D. (2005). A Note on the Normative Dimension of the St. Petersburg Paradox, Studies in the History and Philosophy of Science, ??

- Thaler, R. H., \& Sunstein, C. R. (2003). Libertarian Paternalism. The American Economic Review, 93(2), 175-179.

- Tversky, A., \& Kahneman, D. (1977). Causal Thinking in Judgment under Uncertainty. In R. Butts \& J. Hintekka (Eds.), Basic Problems in Methodology and Linguistics (pp. 167-190). Dordrecht: D. Reichel Publishing Company.

- Tversky, A., \& Krantz, D. H. (1970). The Dimensional Representation and the Metric Structure of Similarity Data. Journal of Mathematical Psychology, 7, 572-596.

- Tversky, A. (1967a). Additivity, utility and subjective probability. Journal of Mathematical Psychology, 4, 175-202.

- Tversky, A. (1967b). A General Theory of Polynomial Conjoint Measurement. Journal of Mathematical Psychology, 4, 1-20.

- Tversky, A. (1969). The intransitivity of preferences. Psychological Review, 76, 3148.

- Tversky, A., \& Kahneman, D. (1971). Belief in the law of small numbers. Psychological Bulletin, 76, 105-110.

- Tversky, A., \& Kahneman, D. (1973). Availability: A heuristic for judging frequency and probability. Cognitive Psychology, 5, 207-232.

- Tversky, A., \& Kahneman, D. (1974). Judgment under Uncertainty: Heuristics and Biases. Science, 185, 1124-1131. 
- Tversky, A., \& Kahneman, D. (1986). Rational Choice and the Framing of Decisions. The Journal of Business, 59(4), S251-S278.

- Tversky, A., \& Kahneman, D. (1992). Advances in Prospect Theory: Cumulative Representation of Uncertainty. Journal of Risk and Uncertainty, 5, 297-323.

- Tversky, A., \& Russo, J. E. (1969). Substitutability and Similarity in Binary Choices. Journal of Mathematical Psychology, 6, 1-12.

- Tversky, A., \& Wakker, P. (1995). Risk Attitudes and Decision Weights. Econometrica, 63(6), 1255-1280.

- Wakker, P., Thaler, R., \& A. Tversky. (1997). Probabilistic Insurance. Journal of Risk and Uncertainty, 15, 7-28.

- Warke, T. (2000). Mathematical Fitness in the Evolution of the Utility Concept from Bentham to Jevons to Marshall. Journal of the History of Economic Thought, 22(1), 527. 